\title{
EVALUATION OF EXTRACTS FROM DRY FRUITS BLACK CURRANT (RIBES NIGRUM L.) THROUGH ONE-DIMENSIONAL AND MULTIDIMENSIONAL REGRESSION ANALYSIS FOR PHENOLCARBOXYLIC ACIDS
}

\author{
Radostina Stefanova, Antoaneta Georgieva, Krasimir Krastev \\ Faculty of Technics and Technologies, Trakia University \\ Graf Ignatiev 38, 8600 Yambol, Bulgaria, e-mail: r_yorgovi@yahoo.com
}

\begin{abstract}
The purpose of the study is to develop a technology for the preparation of blackcurrant extracts. Basic extraction parameters are established. The influence of the technological parameters of the extraction process on the content of phenolcarboxylic acids in the extracts of and currant was analyzed. The extracts obtained were determined with the amount of phenolcarboxylic acids for use in enriching fruit juices with biologically active substances. The effect of the type of extractant, the duration and temperature of the extraction and the hydromodule on the color parameters were investigated. The results of the planned experiment were statistically processed with the Statistica program. The residuals were estimated and analyzed by normal probability of the residual schedule, the scatterplot of the residuals from the predicted values, and the frequency histogram of the residuals. All results are presented analytically and graphically.
\end{abstract}

Keywords: extracts, blackcurrant, phenolecarboxylic acids, regression analysis.

\section{INTRODUCTION}

The production of healthy and wholesome food is an important and priority task related to the development and implementation of functional food products.

One of the conditions for creating a functional product is to achieve the highest possible level of its nutritional and biological value and guaranteed safety.

Drinks are the optimal form of food product that can be used to enrich the diet with essential nutrients and biologically active substances that have a beneficial effect on the metabolism and immune resistance of the body [1].

Studies conducted in different countries confirm that one of the main causes of pathological changes in the human body leading to premature aging and development of cardiovascular diseases, cancer and diabetes is the excessive accumulation of free radicals and reactive oxygen species in the biological fluid of the biological fluid. .

Regular use of fruits and berries in which there are many natural phenolic compounds significantly reduce the risk of these diseases. The largest amount of antioxidants is found in black currant, blackberry, grape, garden strawberry and more. Therefore, it is necessary to include natural plant antioxidants in foods, which protect them from oxidation.

Increasing the content of free radicals in cells creates the conditions for so-called oxidative stress, in which free radicals oxidize the walls of vessels, protein molecules, DNA and lipids. These radicals actively interact with lipid membranes containing unsaturated bonds and alter the properties of cell membranes [2].

The healing potential of wild shrub plants lies in their antioxidant, anti-allergic, antiinflammatory and antiviral properties, which depend on polyphenolic complexes.

Black currant extracts serve as natural antioxidants.

In order to increase the nutritional value and antioxidant properties of the juice-containing beverages, extracts of wild raw materials having prophylactic and functional action can be introduced into production technologies.

IRTITE Vol. 7, No. 4, 2019 ISSN 1314-8788 (print), ISSN 1314-8796 (online), doi: 10.15547/artte.2019.04.008 


\section{ARTTE Y}

Ipplied Resseirlores in Technics, Technologies and Educration

Journal of the Faculty of Technics and Technologies, Trakia University https://sites.google.com/a/trakia-uni.bg/artte/

Small berries black currant, are widely recognized for their nutritional quality and potential health benefits. Black currants are a good source of sugars and organic acids as important primary metabolites, vitamins, antioxidants and phenolic acids that contribute to the quality of taste and aroma [3].

Bordonaba and Terry [4] reported that sugar and acid content and sugar to acid ratio in black currants and other fruits are essential in flavour formation. Also, black currants are an inexhaustible source of vitamins, especially vitamin $\mathrm{C}$, which along with minerals make the fruit highly physiologically valuable. Major minerals and essential trace elements are very important in biological processes, play a vital role in normal growth and development, and are also involved in the prevention of some chronic diseases [5].

The purpose of the study is to develop a technology for the preparation of blackcurrant extracts. Basic extraction parameters are established. The extracts obtained were analyzed for the purpose of enriching fruit juices with phenolic compounds.

\section{MATERIALS AND METHODS}

Object of study are the fruits of Ribes nigrum L. In wild plants are contain a number of chemicals that can affect the vital processes occurring in the human body.

Phenolcarbonic acids - Spectrophotometric by Pharmacopoeia Method [Pharmacopoeia Russia]. General method of analysis [6].

Mathematical data processing was performed by one-dimensional and multi-dimensional regression analysis. By which were studied and evaluated the possible functional dependencies between two or more random variables. The main questions are whether there is a functional dependence between two dependent random variables and if so - to find a function that describes it sufficiently accurately. Various models have been studied, with the best-described dependencies being selected. Estimates were made on the degree of influence of the factors as well as on their level of significance. Fischer's criterion is assessed, as well as its probability. Residue assessment and analysis was performed by normal probability plot of residues, the scatter plot of the predicted residual values and the residual histogram. All results are presented analytically and graphically.

The processing was done through the statistical program STATISTICA (StatSoft, Inc.).

All data are processed at level of significance $\alpha=0,05$.

\section{RESULTS AND DISCUSSION}

The experimental results obtained from the physicochemical studies of the extracts of the dried fruits of the black currant were used to obtain a regression model and to investigate its suitability. Multiple regression was found between phenolecarboxylic acids, $\%$ as a function of response, ethyl alcohol concentration in percentages and time in minutes. The best model turns out to be:

$$
z=b_{1} x+b_{2} y
$$

where $x$ is the time in minutes, $y$ is the temperature in degrees Celsius, and $z$ is the concentration of phenolecarboxylic acids in percent.

After the statistical processing of the data it can be seen that the coefficient of determination $R^{2}=0,90$

, which means that $90 \%$ of the change in the parameter $z$ is due to the control factors $x$ and $y$ and is described with the model used. Of all the models studied, the coefficient of certainty is the highest. The statistically significant coefficients of the model are as follows:

IRTIIE Vol. 7, No. 4, 2019 ISSN 1314-8788 (print), ISSN 1314-8796 (online), doi: 10.15547/artte.2019.04.008 


\section{IRTITE Ipplied Ressearches in Technics, Technologies and Bduciation Journal of the Faculty of Technics and Technologies, Trakia University https://sites.google.com/a/trakia-uni.bg/artte/}

Fisher's criterion, $F(5,41)=25.86, p<0.00000$, and its corresponding probability indicate that the model describes a significant part of the change in $z$. The model performs better than the so-called average estimates.

The regression equation is:

$$
z=0.0118+0.0007^{*} x+0.001^{*} y-3.5544 E-7^{*} x^{*} x-7.025 E-6^{*} x^{*} y+2.2037 E-7^{*} y^{*} y
$$

The resulting regression model describes the surface $z=f(x, y)$, that we can depict in $R^{3}$.

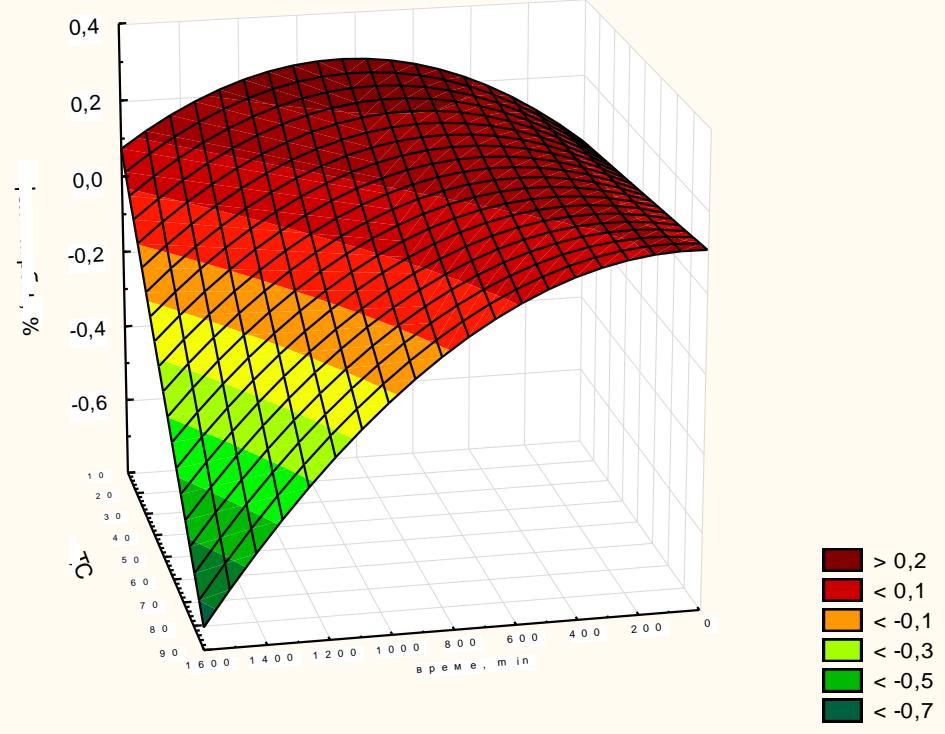

Figure 1. Model response line

The model response line is shown in Figure 1. The analysis of the residuals and their graphical representations are shown in Figure 2 in the so-called normal probability graph.

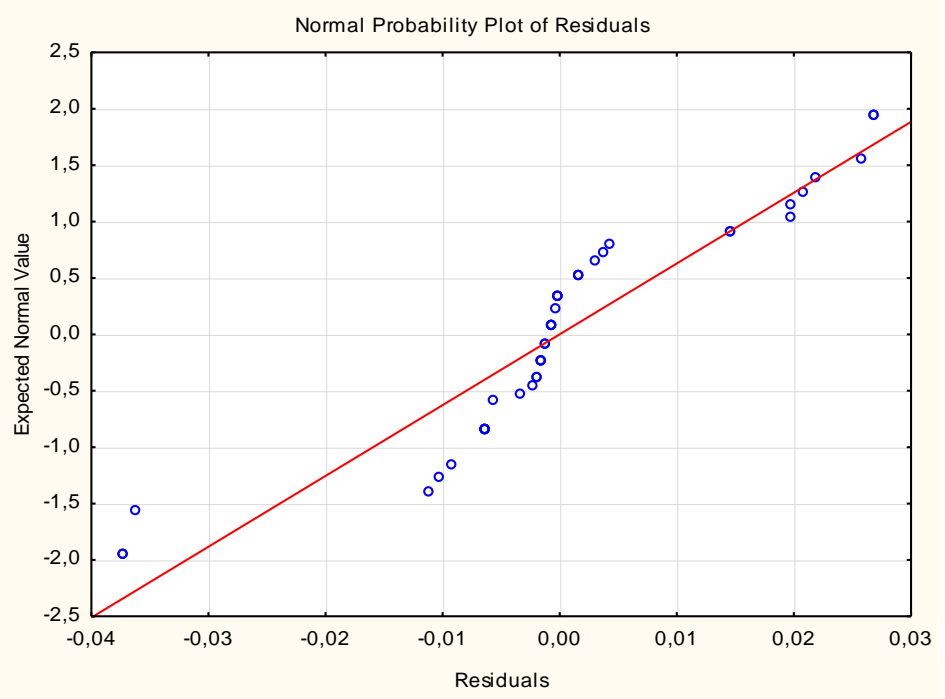

Figure 2. Normal probability plot of residuals

IRTIIE Vol. 7, No. 4, 2019 ISSN 1314-8788 (print), ISSN 1314-8796 (online), doi: 10.15547/artte.2019.04.008 


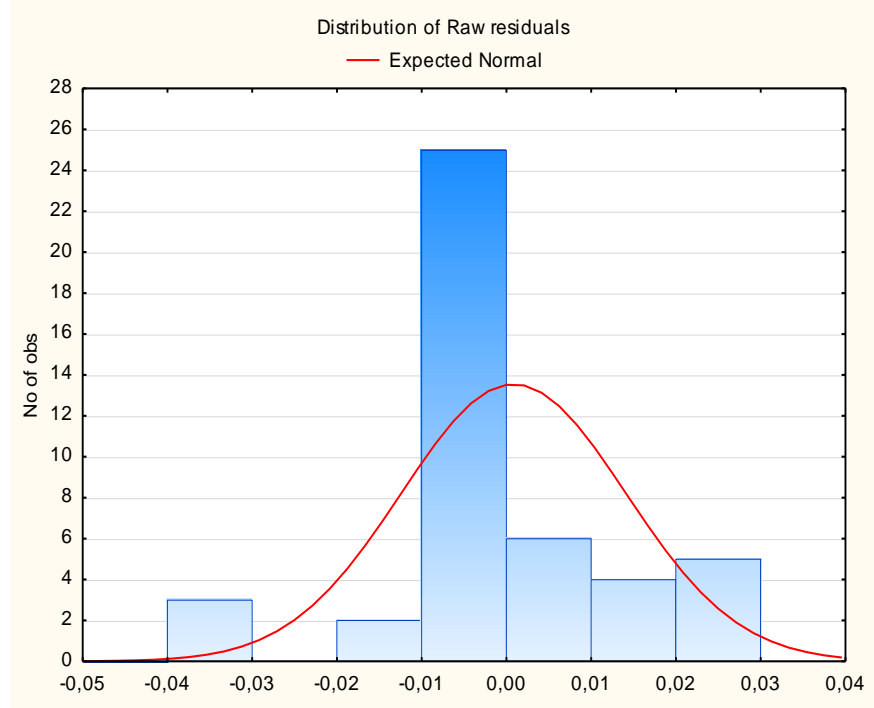

Figure 3. Frequency histogram of residues

The analysis shows a lack of systematic deviation of the actual data from the theoretical curve, which indicates a normal distribution of residues - Figure 3 .

We will check for residual dependence on predicted values from the model. For this purpose, we will analyze the scatterplot of the residuals from the predicted values - Figure 4.

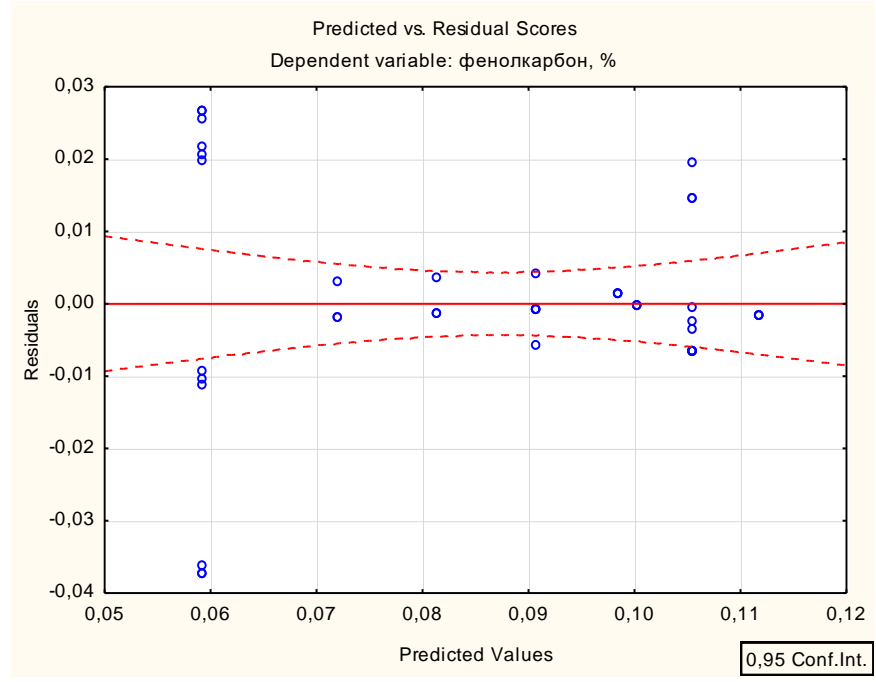

Figure 4. Scatterplot of residual values from predicted values

The obtained graph shows that the residuals are not systematic and are sufficiently chaotic. We can conclude that the residuals do not depend on the predicted values.

From the obtained results we can draw the following conclusions:

- The resulting model is quadratic and describes the experimental data obtained with great precision.

- From the residual analysis, we can conclude that our model is adequate

- From the analysis of standardized bet coefficients, it follows that time and then temperature have the greatest influence on the model.

IRTTE Vol. 7, No. 4, 2019 ISSN 1314-8788 (print), ISSN 1314-8796 (online), doi: 10.15547/artte.2019.04.008 


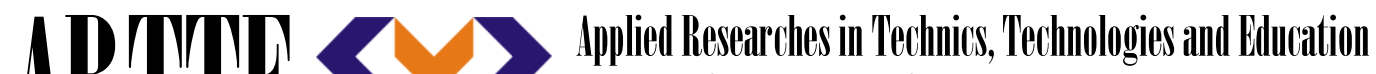 Journal of the Faculty of Technics and Technologies, Trakia University https://sites.google.com/a/trakia-uni.bg/artte/}

The experimental results obtained were also used to obtain a regression model and to find multiple regression between phenolcarboxylic acids, $\%$ as a function of response, ethyl alcohol concentration in percentages and time in minutes. The best model turns out to be:

$$
z=b_{1} x+b_{2} y
$$

where $x$ is the concentration of ethyl alcohol in percent, $y$ is the time in minutes and $z$ is the concentration of phenolecarboxylic acid in percent.

After the statistical processing of the data, it can be seen that the coefficient of determination $R^{2}=0,90$

, which means that $90 \%$ of the change in the parameter $z$ is due to the control factors $x$ and $y$ is described with the model used. Of all the models studied, the coefficient of certainty is the highest. The statistically significant coefficients of the model are as follows:

$$
b_{1}=0,000964, b_{2}=0,000177
$$

Fisher's criterion, $\mathrm{F}(4,41)=107,86, \mathrm{p}<0,00000$, and its corresponding probability indicate that the model describes a significant part of the $z$ change. The model performs better than the so-called naive forecasts by averages.

The regression equation is:

$$
y=0,000964 x+0,000177 y
$$

The resulting regression model describes the surface

$$
z=f(x, y) \text {, that we can depict in }
$$
$R^{3}$.

3D Surface Plot of фенолкарбон, \% against Етил, \% and време, min фенолкарбон_etil+hidro $16 \mathrm{v}^{*} 92 \mathrm{c}$ фенолкарбон, \% $=0,0248+0,001^{*} \mathrm{x}-1,9156 \mathrm{E}-6^{*} \mathrm{y}$

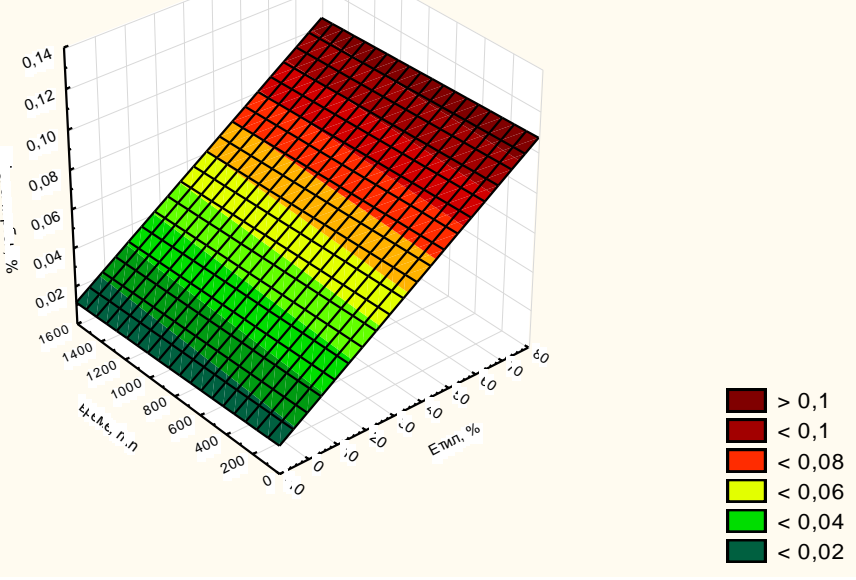

Figure 5. Model response line 


\section{IRTILV}

Ipplied Resseirlohes in Technics, Technologies and Eductition

Journal of the Faculty of Technics and Technologies, Trakia University https://sites.google.com/a/trakia-uni.bg/artte/

The model response line is shown in Figure 5. The analysis of the residuals and their graphical representations are depicted in Figure 6 in the so-called normal probability graph.

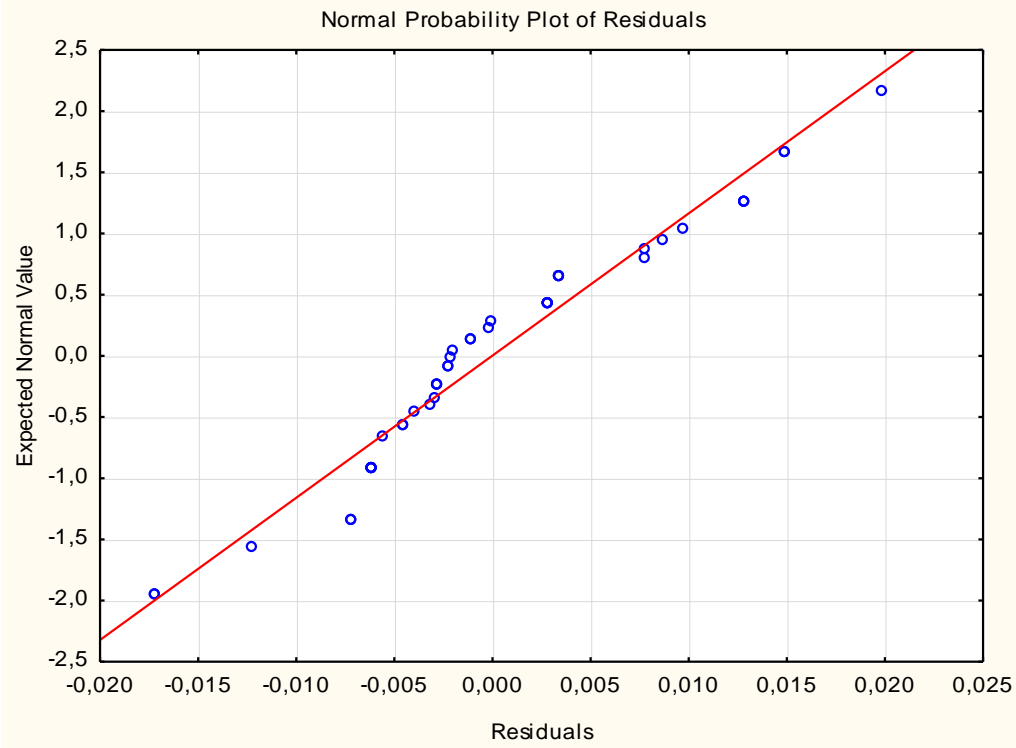

Figure 6. Normal probability plot of residuals

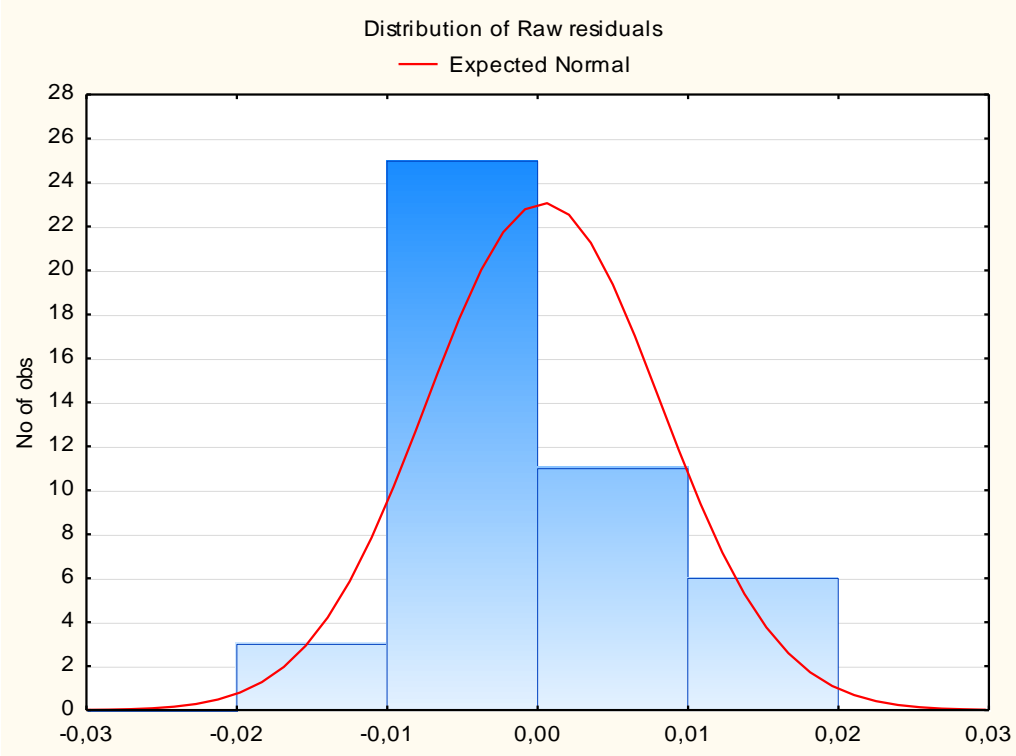

Figure 7. Frequency histogram of residues

The analysis shows a lack of systematic deviation of the actual data from the theoretical curve, which indicates a normal distribution of residues - Figure 7.

We will check for residual dependence on predicted values from the model. For this purpose, we will analyze the scatterplot of the residuals from the predicted values - Figure 8.

IRTIIE Vol. 7, No. 4, 2019 ISSN 1314-8788 (print), ISSN 1314-8796 (online), doi: 10.15547/artte.2019.04.008 


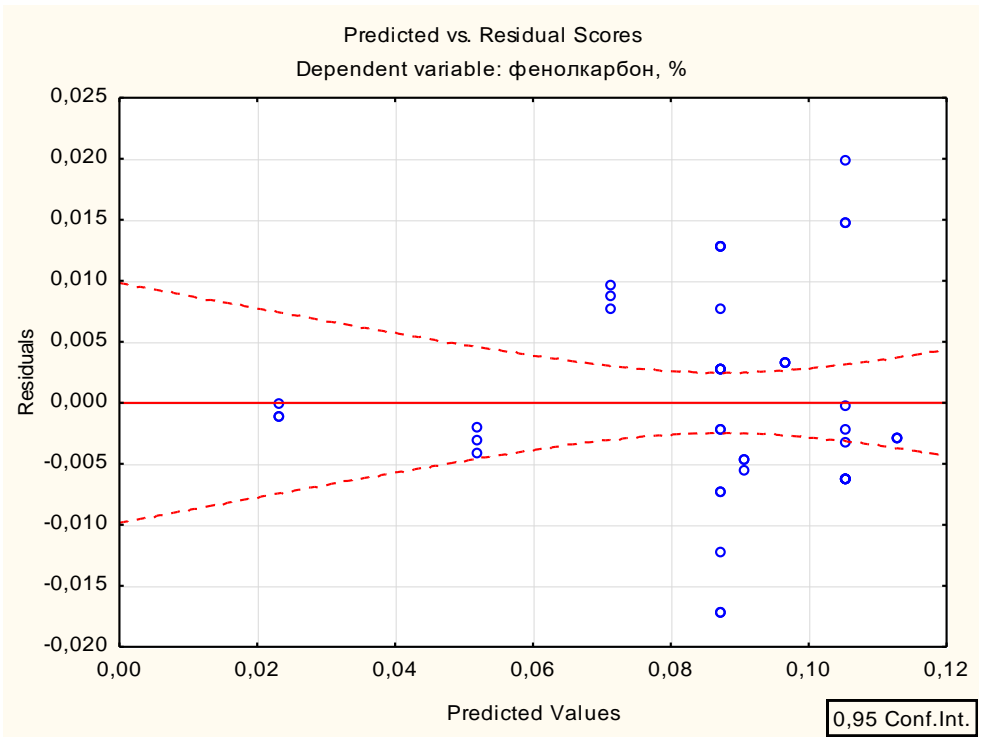

Figure 8. Scatterplot of residual values from predicted values

The obtained graph shows that the residuals are not systematic and are sufficiently chaotic. We can conclude that the residuals do not depend on the predicted values.

From the obtained results we can draw the following conclusions:

- The resulting model is linear describes the experimental data obtained with great precision.

- From the residual analysis, we can conclude that our model is adequate.

- From the analysis of standardized bet coefficients, it follows that time and then concentration have the greatest influence on the model.

The experimental results obtained were also used to obtain a regression model and to search for multiple regression between phenolecarboxylic acids, $\%$ as a function of response, ethyl alcohol concentration in percent and temperature.

The best model turns out to be:

$$
z=b_{0}+b_{1} x+b_{2} y
$$

where $\mathrm{x}$ is the concentration of ethyl alcohol in percent, $\mathrm{y}$ is the temperature, and $\mathrm{z}$ is the concentration of phenolecarboxylic acid in percent.

After the statistical processing of the data it can be seen that the coefficient of determination $R^{2}=0,86$

which means that $86 \%$ of the change in the parameter $z$ is due to the control factors $x$ and $y$ and is described with the model used. Of all the models studied, the coefficient of certainty is the highest. The statistically significant coefficients of the model are as follows:

$$
b_{0}=0,018221, b_{1}=0,000805, b_{2}=0,000378
$$

Fisher's criterion, $F(4,42)=100,41, p<0,00000$, and its corresponding probability indicate that the model describes a significant part of the change in $z$. The model performs better than the so-called average estimates.

IRTIIE Vol. 7, No. 4, 2019 ISSN 1314-8788 (print), ISSN 1314-8796 (online), doi: 10.15547/artte.2019.04.008 


\section{IRTILE} Ipplied Resseirlohes in Technics, Technologies and Eductition Journal of the Faculty of Technics and Technologies, Trakia University https://sites.google.com/a/trakia-uni.bg/artte/

The regression equation is:

$$
y=0,018221+0,000805 x+0,000378 y
$$

The resulting regression model describes the surface $z=f(x, y)$, that we can depict in $R^{3}$.

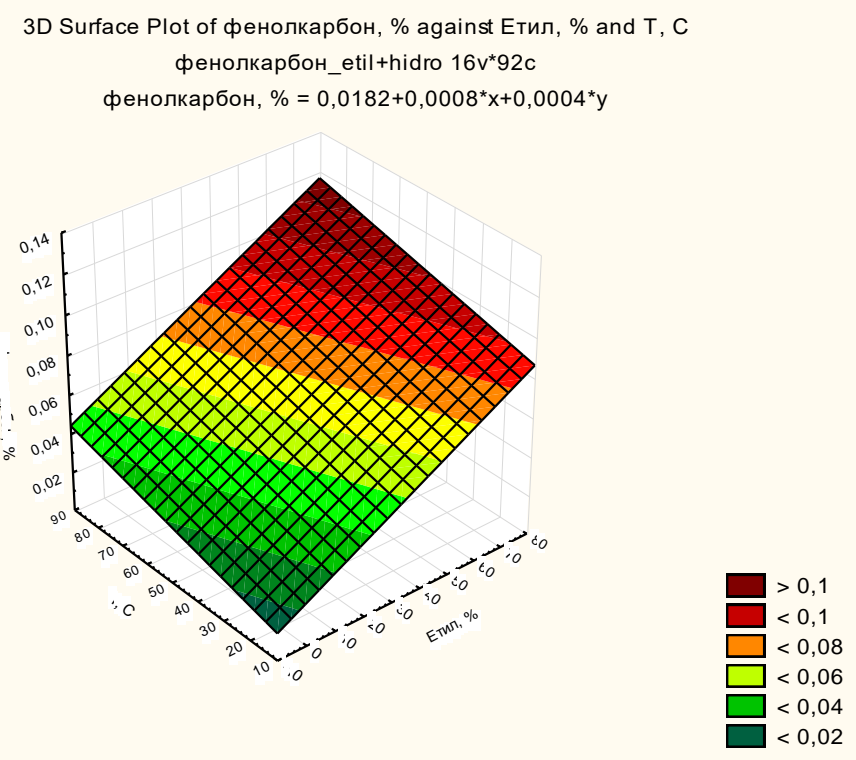

Figure 9. Model response line

The model response line is presented in Figure 9. The analysis of residuals and their graphical representations are shown in Figure 10 in the so-called normal probability graph.

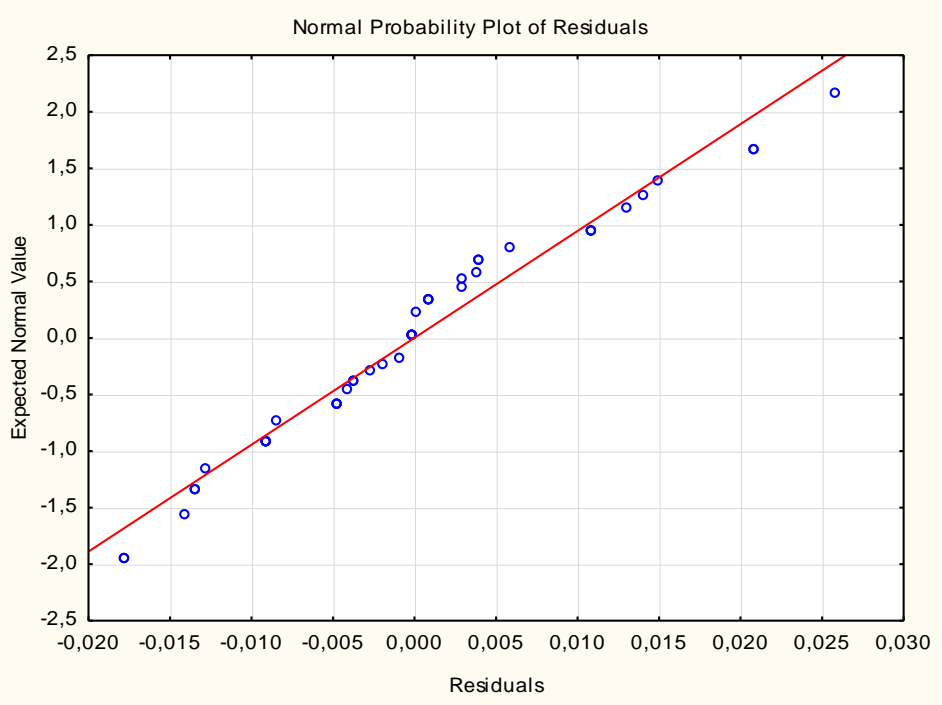

Figure 10. Normal probability plot of residuals

IRTIIE Vol. 7, No. 4, 2019 ISSN 1314-8788 (print), ISSN 1314-8796 (online), doi: 10.15547/artte.2019.04.008 


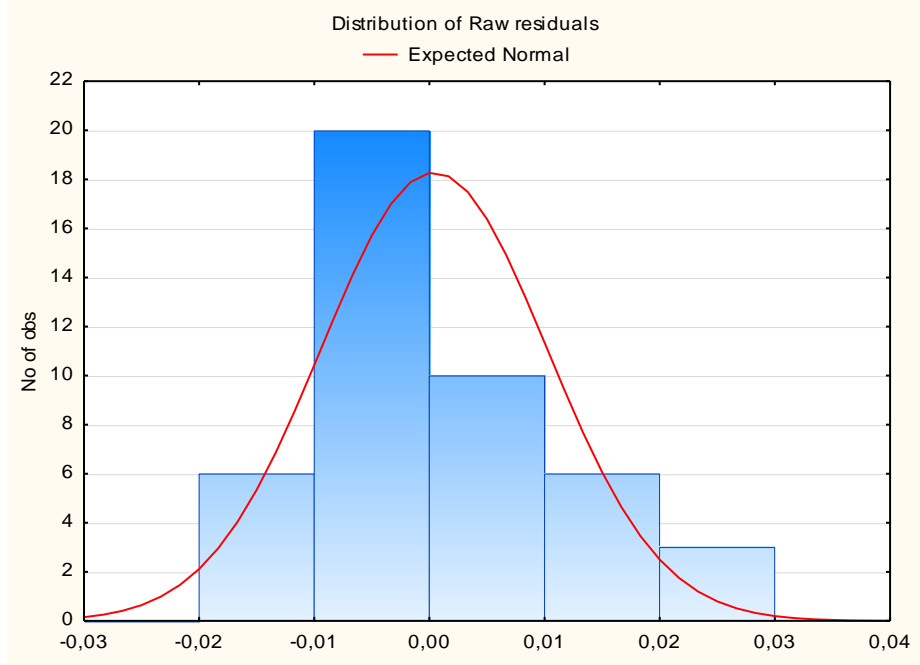

Figure 11. Frequency histogram of residues

The analysis shows a lack of systematic deviation of the actual data from the theoretical curve, which indicates a normal distribution of residues - Figure 11.

We will check for residual dependence on predicted values from the model. For this purpose, we will analyze the scatterplot of the residuals from the predicted values - Figure 12.

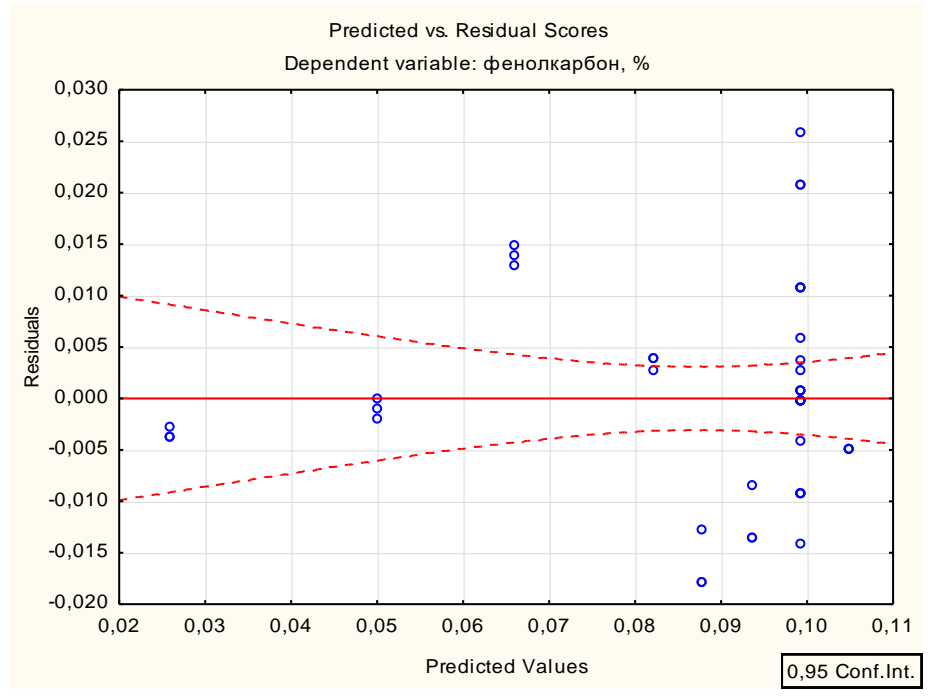

Figure 12. Scatterplot of residual values from predicted values

The obtained graph shows that the residuals are not systematic and are sufficiently chaotic. We can conclude that the residuals do not depend on the predicted values.

From the obtained results we can draw the following conclusions:

- The resulting model is linear and describes with great precision the experimental data obtained.

- From the residual analysis, we can conclude that our model is adequate.

- From the analysis of standardized bet coefficients, it follows that concentration and then temperature have the greatest influence on the model.

IRTIIE Vol. 7, No. 4, 2019 ISSN 1314-8788 (print), ISSN 1314-8796 (online), doi: 10.15547/artte.2019.04.008 


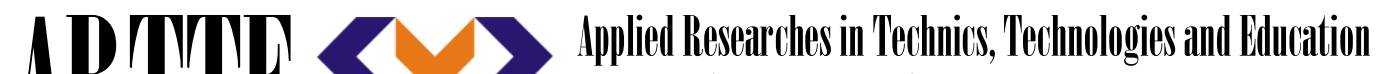 Journal of the Faculty of Technics and Technologies, Trakia University https://sites.google.com/a/trakia-uni.bg/artte/}

The results of the physicochemical studies of the extracts of the black currant fruits were used to obtain a regression model for finding multiple regression between phenolecarboxylic acids, \% as a function of response and concentration of ethyl alcohol in percent and hydromodule.

The best model turns out to be:

$$
z=b_{1} x+b_{2} y
$$

where $\mathrm{x}$ is the concentration of ethyl alcohol in percent, $\mathrm{y}$ is the hydromodule, and $\mathrm{z}$ is the concentration of phenolcarboxylic acid in percent.

After the statistical processing of the data it can be seen that the coefficient of determination $R^{2}=0,86$, which means that $86 \%$ of the change in the parameter $z$ is due to the control factors $x$ and $y$ and is described with the model used. Of all the models studied, the coefficient of certainty is the highest. The statistically significant coefficients of the model are as follows:

$$
b_{1}=0,001008, b_{2}=0,001359
$$

Fisher's criterion, $F(4,42)=126.32, p<0.00000$, and its corresponding probability indicate that the model describes a significant part of the change in $z$. The model performs better than the average estimates.

The regression equation is:

$$
y=0,001008 x+0,001359 y
$$

The resulting regression model describes the surface $z=f(x, y)$, that we can depict in $R^{3}$

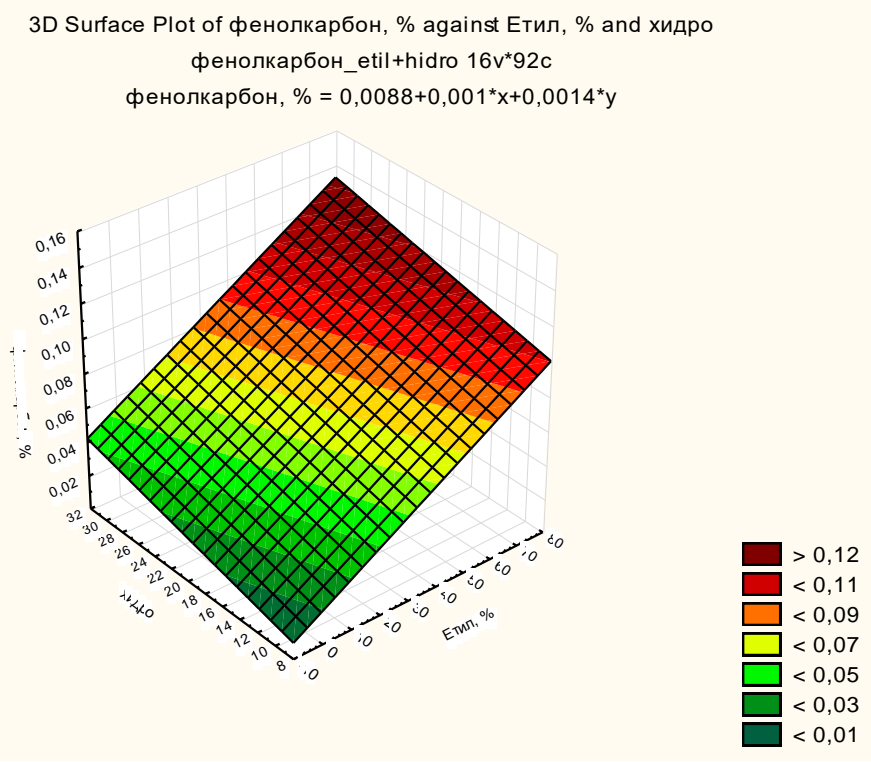

Figure 13. Model response line

IRTIIE Vol. 7, No. 4, 2019 ISSN 1314-8788 (print), ISSN 1314-8796 (online), doi: 10.15547/artte.2019.04.008 


\section{IRTITE}

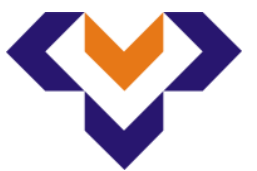

Ipplied Resererr'ches in Technics, Technologies and Bduration

Journal of the Faculty of Technics and Technologies, Trakia University https://sites.google.com/a/trakia-uni.bg/artte/

The model response line is presented in Figure 13. The analysis of the residuals and their graphical representations are depicted in Figure 14 in the so-called normal probability graph.

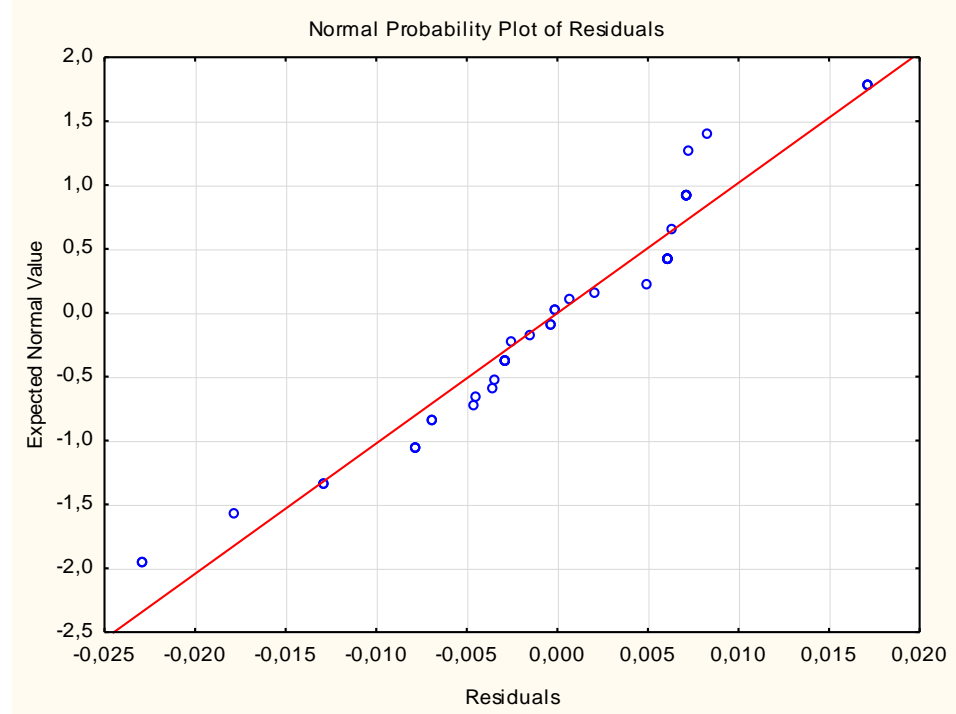

Figure 14. Normal probability plot of residuals

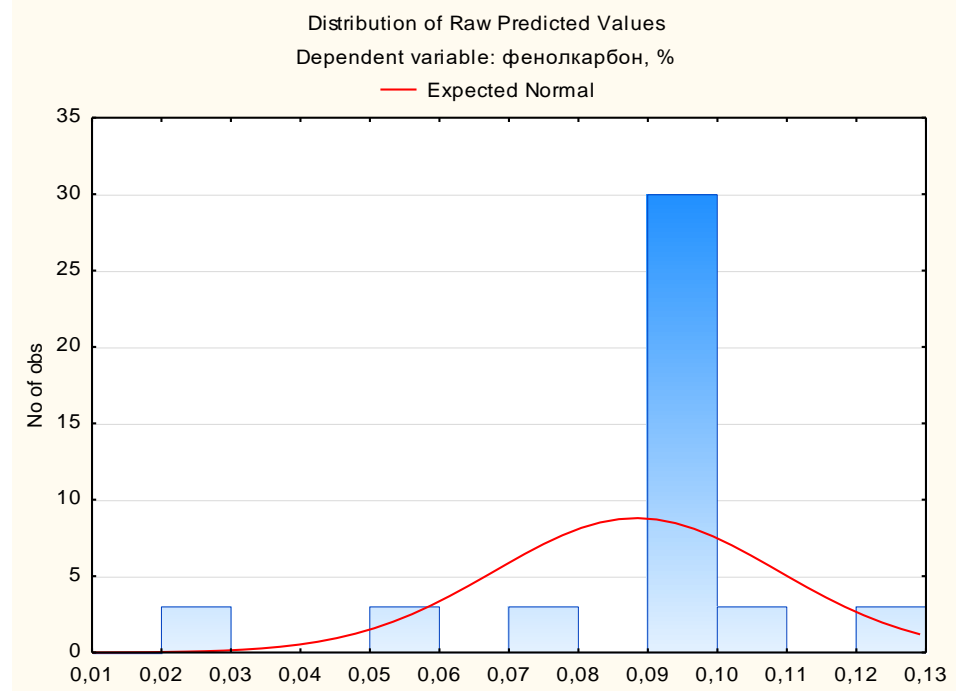

Figure 15.Frequency histogram of residues

The analysis shows a lack of systematic deviation of the actual data from the theoretical curve, which indicates a normal distribution of residues - Figure 15.

We will check for residual dependence on predicted values from the model. For this purpose, we will analyze the scatterplot of the residuals from the predicted values - Figure 16.

IRTIIE Vol. 7, No. 4, 2019 ISSN 1314-8788 (print), ISSN 1314-8796 (online), doi: 10.15547/artte.2019.04.008 


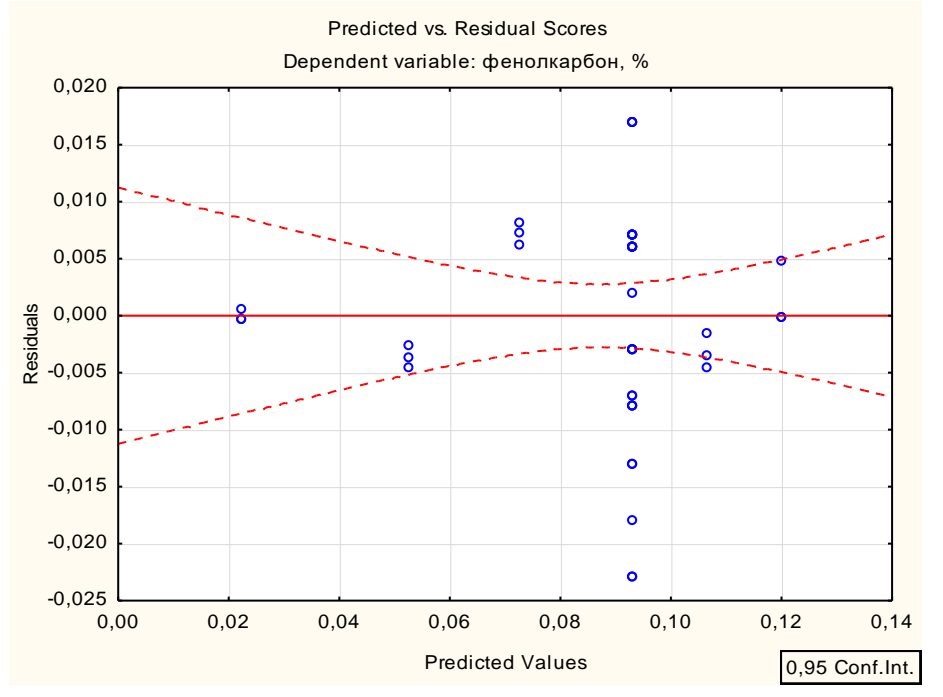

Figure 16. Scatterplot of residual values from predicted values

The obtained graph shows that the residuals are not systematic and are sufficiently chaotic. We can conclude that the residuals do not depend on the predicted values.

\section{CONCLUSION}

From the obtained results we can draw the following conclusions:

- The resulting model is linear and describes with great precision the experimental data obtained.

- From the residual analysis, we can conclude that our model is adequate.

- From the analysis of standardized bet coefficients, it follows that the concentration and then the hydromodule have the greatest influence on the model.

\section{REFERENCES}

[1] Akulinina V. (2007). Enriched drinks - a new niche in the juice market. Container and packaging, No. 4, p.16. (in Russian).

[2] Yashin Y. I. (2009). Natural antioxidants. Content in Foods and Their Impact on Human Health and Aging, TransLit, p. 212. (in Bulgarian).

[3] Hartmann T. (2007). From waste products to ecochemicals: Fifty years research of plant secondary metabolism. Phytochemistry, Vol. 68, pp. 2831-2846.

[4] Bordonaba G. J., A. L. Terry. (2008). Biochemical profiling and chemometric analysis of seventeen UK-grown black currant cultivars (Ribes nigrum L.). Journal of Agricultural and Food Chemistry, Vol. 56, pp. 7422-7430.

[5] Gorinstein S., Z. Zachwieja, M. Folta, H. Barton, J. Piotrowicz, M. Zemser, M. Weisz, S. Trakhtenberg, O. Martin-Belloso. (2001). Comparative contents of dietary fiber, total phenolics, and minerals in persimmons and apples. Journal of Agricultural and Food Chemistry, Vol. 49, pp. 952-957.

[6] State Pharmacopoeia of Russia. General methods of analysis - II ed. Medicine, 1987. 